\title{
Dispersão de sementes e densidade populacional de Psychotria nuda (Rubiceae) em fragmento urbano de Floresta Ombrófila Densa de Terras Baixas no sul do Brasil
}

\author{
Bianca Raboch Tierschnabel * \\ João Carlos Ferreira de Melo Júnior \\ Sidnei da Silva Dornelles \\ Programa de Pesquisa em Ciências Ambientais, Universidade da Região de Joinville \\ Rua Paulo Malschitzki, 10, CEP 89219-710, Joinville - SC, Brasil \\ * Autor para correspondência \\ biancaraboch@hotmail.com
}

Submetido em 13/11/2017

Aceito para publicação em 16/04/2018

\section{Resumo}

O presente trabalho objetivou reconhecer os agentes dispersores de Psychotria nuda num fragmento de Floresta Atlântica e estimar a sua densidade populacional. A área de estudo compreende um fragmento de floresta ombrófila em estádio médio de regeneração. A densidade populacional foi estimada em área de 1 ha. $\mathrm{O}$ padrão de distribuição da espécie foi determinado pelo índice de Morisita. Vinte indivíduos adultos foram observados para determinação de dispersores e mais dez para avaliar a eficácia do tipo de dispersão mediante marcação de frutos e instalação de redes coletoras. Em 1 ha foram registrados 1.131 indivíduos. O índice de Morisita encontrado para a população foi de 1,317, sinalizando padrão agregado de distribuição. Os resultados obtidos para a dispersão mostraram que a barocoria é mais frequente que a zoocoria. Foi registrada apenas Tachyphonus coronatus (tiêpreto) como ave dispersora de P. nuda. Conclui-se que o padrão de distribuição agregado encontrado pode estar relacionado com a falta de um agente dispersor mais eficiente quando comparado à dispersão barocórica, o que justifica o padrão de distribuição agregado. Em termos populacionais, a espécie apresenta uma taxa balanceada entre recrutamento e morte de indivíduos, garantindo sua ocorrência no fragmento florestal.

Palavras-chave: Conservação da biodiversidade; Dispersão barocórica; Dispersão zoocórica; Estrutura populacional; Mata Atlântica

\section{Abstract}

Seed dispersal and population density of Psychotria nuda (Rubiceae) in an urban fragment of dense ombrophilous lowland forest in southern Brazil. The present study aimed to identify the dispersal agents of Psychotria nuda in an Atlantic Forest fragment and to estimate the population density of this species. The study area comprises an ombrophilous forest fragment at an intermediate regeneration stage. The population density was estimated in a 1 ha area. The species distribution pattern was determined using the Morisita index. Twenty adult individuals were observed to determine the dispersers and ten more were studied to evaluate the efficacy of the dispersal type by marking fruits and installing collecting nets. In the 1 ha area, 1,131 individuals were recorded. The Morisita index found a population of 1,317, indicating an aggregate distribution pattern. 
The results obtained for dispersal showed that barochory is more frequent then zoochory. Only Tachyphonus coronatus (ruby-crowned tanager) was recorded as a bird that disperses $P$. nuda. It is concluded that the aggregate distribution pattern found may be related to the absence of an efficient dispersal agent compared to barochory, which justifies the pattern. In population terms, $P$. nuda presents a balanced rate between recruitment and death of individuals, guaranteeing the occurrence of this species in the forest fragment.

Key words: Barochory; Biodiversity conservation; Population structure; Rain Forest; Zoochory

\section{Introdução}

A Mata Atlântica, considerada um dos ecossistemas mais ricos em se tratando da diversidade biológica, abriga de 1 a $8 \%$ de toda a biodiversidade mundial (LAGOS; MULLER, 2007) e está entre um dos 25 hotspots mundiais de biodiversidade (MYERS et al., 2000; SILVA; CASTELETI, 2005). Distribuída ao longo de mais de 27 graus de latitude sul, com grandes variações de altitude e longitude, é composta por distintas formações fitogeográficas que abrigam diversas formas de vida (IBGE, 2012), cuja excepcional riqueza é caracterizada pelo acentuado endemismo de espécies (MYERS et al., 2000; SILVA; CASTELETI, 2005). Apesar de extremamente diversificada e do alto interesse ecológico, a fragmentação de habitat é uma das mais difundidas consequências da equivocada dinâmica de uso da terra pela sociedade humana e que tem afetado historicamente a Mata Atlântica (TABARELLI; GASCON, 2005). Em função da incessante perda de habitat, as florestas remanescentes continuam a ser degradadas (GALETTI; FERNANDEZ, 1998; TABARELLI et al., 2004) e divididas em diversos fragmentos (ROCHA et al., 2003), muitas vezes isolados e de dimensões inferiores a 100 ha (MMA, 2016).

Com vistas à recuperação e manutenção dos fragmentos florestais remanescentes da Floresta Atlântica, os quais se configuram como áreas relictuais da sua biodiversidade, a dispersão de sementes está estreitamente relacionada aos processos de recuperação de áreas degradadas e de regeneração natural, uma vez que os dispersores atuam como catalisadores sucessionais, acelerando a recolonização da vegetação nativa (ROBINSON; HANDEL, 1993; WUNDERLE JR., 1997).
Espécies arbóreas nas florestas tropicais são, em grande escala, dispersas por animais e essa dependência é decorrente de várias características atrativas como morfologia, oferta de reservas nutricionais, cor e odor dos frutos. Na Mata Atlântica, 45 a 90\% das árvores dependem de vertebrados para a dispersão de sementes, sendo as aves os dispersores exclusivos de quase $40 \%$ das espécies arbóreas (ALMEIDA-NETO et al., 2008). A interação ave-planta resulta num padrão assimétrico, no qual poucas aves interagem com muitas plantas ou poucas plantas interagem com muitas aves (JORDANO, 1987). Como estratégia de dispersão, algumas plantas tendem a investir em maior quantidade de sementes por fruto, aumentando sua probabilidade absoluta de sucesso de recolonização (WIESBAUER et al., 2008).

Entre as famílias botânicas produtoras de frutos carnosos e de elevada importância ecológica no subbosque da Floresta Atlântica, pode ser citada a família Rubiaceae, a qual encontra-se extensamente distribuída nas regiões tropicais e subtropical do mundo (GOMES, 1996; BFG, 2015). O gênero Psychotria L. é o maior da família, com cerca de 1.500 espécies (JUDD et al., 2010) de distribuição tropical, e produz frutos carnosos consumidos por vertebrados, incluindo pássaros (ALMEIDA; ALVES, 2000). Estudos sobre a dispersão e interações de Psychotria nuda (Cham \& Schltdl.) Wawra (Rubiceae) com animais ainda são muito incipientes. Dados sobre fenologia e dispersão dessa espécie podem ser observados em esparsos estudos no Brasil. Estudos desenvolvidos com Psychotria nuda de Floresta Ombrófila Densa da região sudeste do Brasil têm buscado relacionar os eventos fenológicos à sazonalidade e identificar as espécies de aves que dispersam seus frutos, além de estabelecer a relação entre forrageamento e concentração de açúcares nos diásporos de dispersão (ALMEIDA; ALVES, 2000; ALMEIDA et al., 2006). Entretanto, estudos que buscam 
compreender essas interações que são desconhecidas na Floresta Ombrófila Densa de Terras Baixas em Santa Catarina são ainda incipientes.

O presente estudo objetivou estimar a densidade populacional de Psychotria nuda em um fragmento de Floresta Ombrófila Densa de Terras Baixas e, a partir do reconhecimento dos seus agentes dispersores, inferir sobre a dispersão potencial dessa espécie. São hipóteses deste estudo: a) $P$. nuda possui poucas espécies de animais dispersores; b) para a população estudada a dispersão barocórica é mais utilizada que a zoocórica; c) $P$. nuda possui padrão de distribuição agregado no fragmento em estudo.

\section{Material e Métodos}

\section{Área de estudo}

O estudo foi realizado em um fragmento de Floresta Ombrófila Densa de Terras Baixas, localizado na porção norte de Joinville, estado de Santa Catarina, próximo à zona industrial da cidade e situado nas coordenadas geográficas: $26^{\circ} 15,20,02 " \mathrm{~S}$ e $48^{\circ} 51$ '21,02” W (Figura 1). O fragmento possui 13 ha de área florestal em estádio médio de regeneração (ARRIOLA; MELO JÚNIOR, 2017). O clima da região é Cfa (ALVARES et al., 2013), caracterizado como clima subtropical úmido com verões quentes e sem

FIGURA 1: Localização espacial e respectivo climatograma do fragmento de Floresta Ombrófila Densa de Terras Baixas, Joinville, Santa Catarina, utilizado como área amostral para a estimativa da densidade populacional de Psychotria nuda (Rubiaceae) e sua inter-relação com a fauna dispersora.

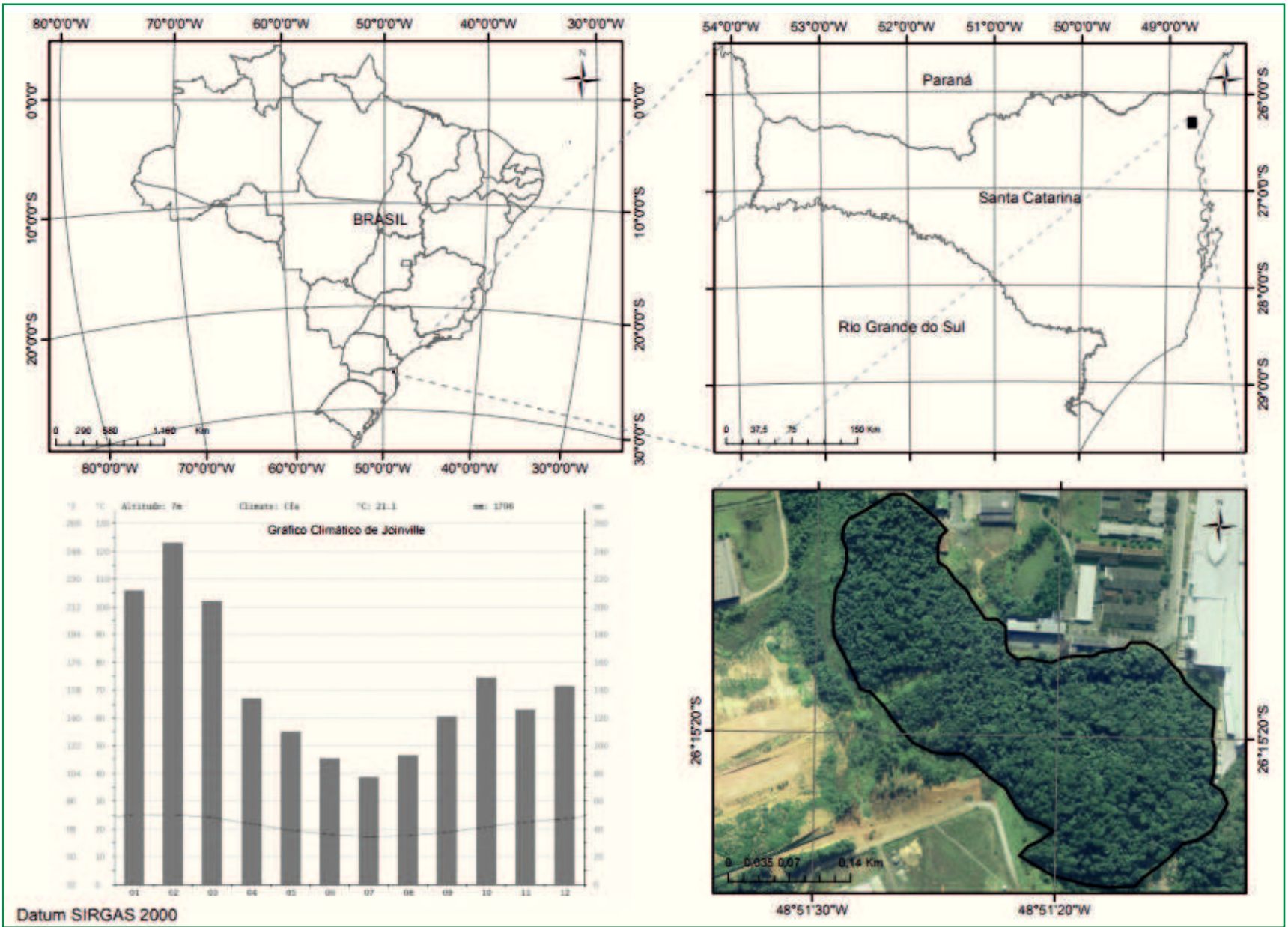


estação seca definida. Apresenta temperatura média anual de $21,1^{\circ} \mathrm{C}$, sendo janeiro o mês mais quente e julho o mês mais frio. A precipitação média anual é de $1.706 \mathrm{~mm}$, sendo o mês de fevereiro o mais chuvoso, com precipitação média de 246 mm (CLIMATE-DATE, 2017).

\section{A espécie em estudo}

A espécie Psychotria nuda, conhecida como grandiúva-d'anta, flor-de-cera ou casca-de-anta é nativa do Brasil e é encontrada na Floresta Ombrófila Densa da encosta atlântica nos estados de Minas Gerais, Rio de Janeiro, Espírito Santo, São Paulo, Paraná, Santa Catarina e Rio Grande do Sul (DELPRETE et al., 2005; TAYLOR, 2007). É uma espécie tida como zoocórica e de classe sucessional secundária tardia (MELO, 2000), esciófita, higrófita, situada nos estratos inferiores de florestas primárias bem desenvolvidas (IZA, 2002; FERMINO JUNIOR et al., 2004; GORENSTEIN, 2007; PRATA et al., 2011) e que também se distribui em formações secundárias. Possui padrão de distribuição agregado com cerca de 144 indivíduos/ha (ALMEIDA; ALVES, 2000). Apresenta forma de vida arbustiva ou arvoreta de 1,5-4 $\mathrm{m}$ de altura, muito ramificada, que floresce de fevereiro a junho e frutifica no outono e inverno (ALMEIDA; ALVES, 2000; DELPRETE et al., 2005). Seu fruto é drupáceo, elipsoide, de cor azul a violáceo, com sementes plano-convexas, castanhoclaras, superfície ventral plana, com sulco longitudinal e superfície dorsal com uma única costela (PEREIRA et al., 2006).

\section{Registro da dispersão}

As observações, realizadas de abril a agosto de 2017, foram feitas em 10 indivíduos adultos de P. nuda em seis períodos completos de $12 \mathrm{~h}$, das $06 \mathrm{~h} 00 \mathrm{~min}$ às 18h00min, totalizando $72 \mathrm{~h}$ de esforço amostral (PIZO, 1997). Nas observações focais foram registradas as espécies de aves consumidoras de fruto, o número de visita de cada espécie, o horário da visita e o tratamento dado aos frutos. As observações foram feitas de 10 a 15 $m$ de distância dos indivíduos amostrais, com binóculos e registro fotográfico. A identificação da avifauna foi feita por meio de guia de campo da avifauna brasileira
(SIGRIST, 2009) e por consulta a banco de dados em literatura específica.

Para a análise da dispersão barocórica foram selecionados 10 indivíduos adultos que continham o maior número de frutos no período estudado. Abaixo de cada um desses indivíduos foi instalada uma rede de filó suspensa a 1,5 m do chão, com a finalidade de coletar os frutos dispersos por barocoria. Foram marcados 10 frutos em cada indivíduo amostral e os ramos correspondentes aos respectivos frutos. Após as marcações, foram feitas observações diárias e contagem dos frutos marcados presentes sobre a rede ou ainda fixados aos ramos.

A eficácia do tipo de dispersão foi testada por meio do teste de contingência, com $\alpha=0,05$, em ambiente estatístico R (BORCARD et al., 2011).

\section{Densidade e estrutura populacional}

Para a avaliação da densidade populacional de Psychotria nuda foram alocadas em campo 100 parcelas de $10 \times 10 \mathrm{~m}\left(100 \mathrm{~m}^{2}\right)$ com distribuição uniforme no fragmento, evitando bordas, clareiras e áreas antropizadas. Em cada parcela foi registrado o número de indivíduos da espécie em estudo, a altura e o diâmetro do caule à altura do peito (DAP). Para estimar sua densidade populacional, os indivíduos amostrados foram divididos em três classes de desenvolvimento: a) regeneração (plântulas com até dez pares de eófilos); b) juvenil (não reprodutiva); c) adulta (reprodutiva). $\mathrm{O}$ padrão de distribuição da espécie foi determinado por meio do índice de dispersão de Morisita (Id) (BROWER; ZAR, 1984) e a significância do Id testada por meio do teste F (POOLE, 1974).

\section{Resultados}

\section{Dispersão}

Foram registradas 26 interações da espécie Tachyphonus coronatus (Vieillot, 1822) (Thraupidae) com Psychotria nuda (Figura 2), sendo essa a única espécie dispersora da planta focal no fragmento em estudo. 
FIGURA 2: Dispersão de sementes de Psychotria nuda (Rubiaceae) em fragmento de Floresta Ombrófila Densa de Terras Baixas, Joinville, Santa Catarina.
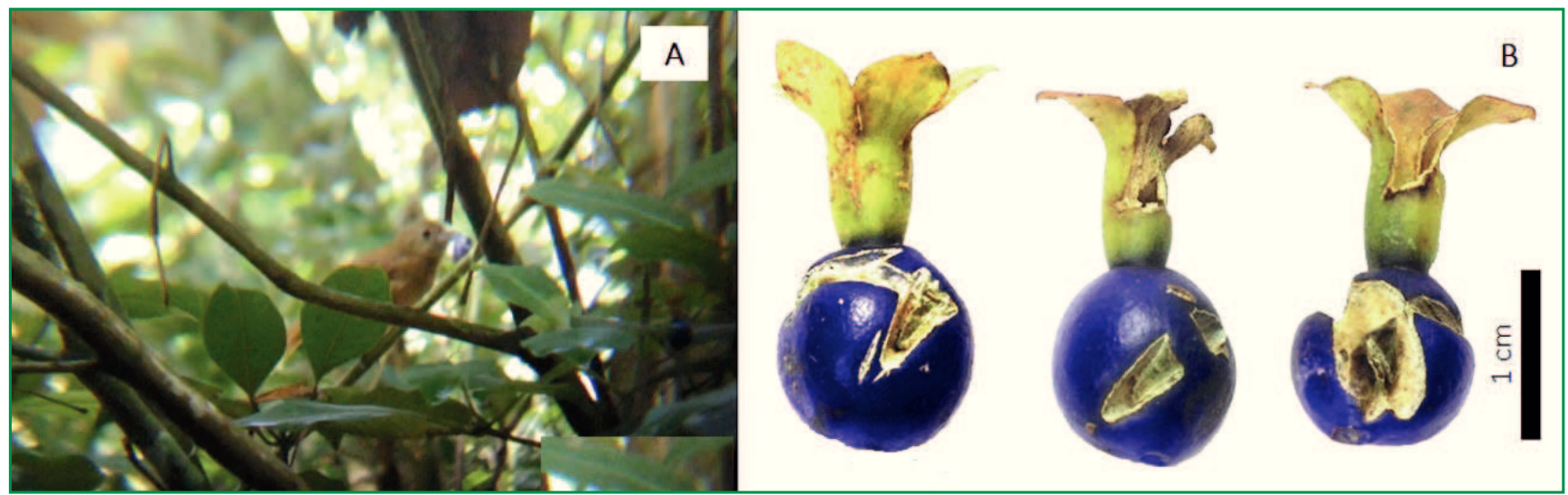

Legenda: A - Interação de Tachyphonus coronatus (Vieillot, 1822) (Thraupidae) com P. nuda. B - Frutos de P. nuda encontrados no coletor de frutos com marcas de frugivoria.

Dos 100 frutos marcados em campo, 72 foram encontrados depositados sobre a rede coletora de frutos e destes, nove frutos possuíam marcas de frugivoria (Figura 2) e nove não foram encontrados. O teste do quiquadrado indicou a significância da dispersão barocórica sobre a ornitócorica $\left(\chi^{2}=97,09 ; \mathrm{gl}=2 ; \mathrm{p}=0,0001\right)$.

\section{Densidade e estrutura populacional}

Foram observados 1.131 indivíduos distribuídos em 3 classes de desenvolvimento em uma área amostral total de 1 ha. Registrou-se para a classe de plântula um total de 402 indivíduos, para a classe juvenil 565 indivíduos e 164 para a classe de adultos. O valor do Índice de Dispersão de Morisita (Id) obtido para a população total foi de 1,317 e indica o padrão de distribuição agregado para a população $P$. nuda em estudo. Quando calculado o Id de forma independente para as três classes sucessionais, o resultado corrobora o encontrado para a população total (Tabela 1). A população estudada apresentou poucos indivíduos na classe de adulto e um maior número de indivíduos nas classes juvenil e de plântula com evidente redução em altura e diâmetro (Figura 3; Figura 4).

TABELA 1: Estrutura populacional de Psychotria nuda (Rubiaceae) em áreas de Floresta Ombrófila Densa de Terras Baixas, Joinville, SC.

\begin{tabular}{lcccc}
\hline Classe & Id & $\mathbf{N}$ & $\mathbf{H}$ & DAP \\
\hline Plântulas & 1,330 & 402 & $0,27 \pm 0,13$ & $0,36 \pm 0,14$ \\
Jovens & 1,430 & 565 & $1,16 \pm 0,58$ & $1,28 \pm 0,73$ \\
Adultos & 1,833 & 164 & $2,54 \pm 0,89$ & $3,64 \pm 2,57$ \\
\hline Total & $\mathbf{1 , 3 1 7}$ & $\mathbf{1 1 3 1}$ & $\mathbf{1 , 0 5} \pm \mathbf{0 , 9 1}$ & $\mathbf{1 , 3 0} \pm \mathbf{1 , 5 2}$ \\
\hline
\end{tabular}

Legenda: Id = Índice de Dispersão de Morisita; $\mathrm{N}$ = abundância; $\mathrm{H}=$ altura (em metros); DAP = diâmetro à altura do peito (em centímetros). 
FIGURA 3: Classes diamétricas de Psychotria nuda (Rubiaceae) em Floresta Ombrófila Densa de Terras Baixas, Joinville, SC.

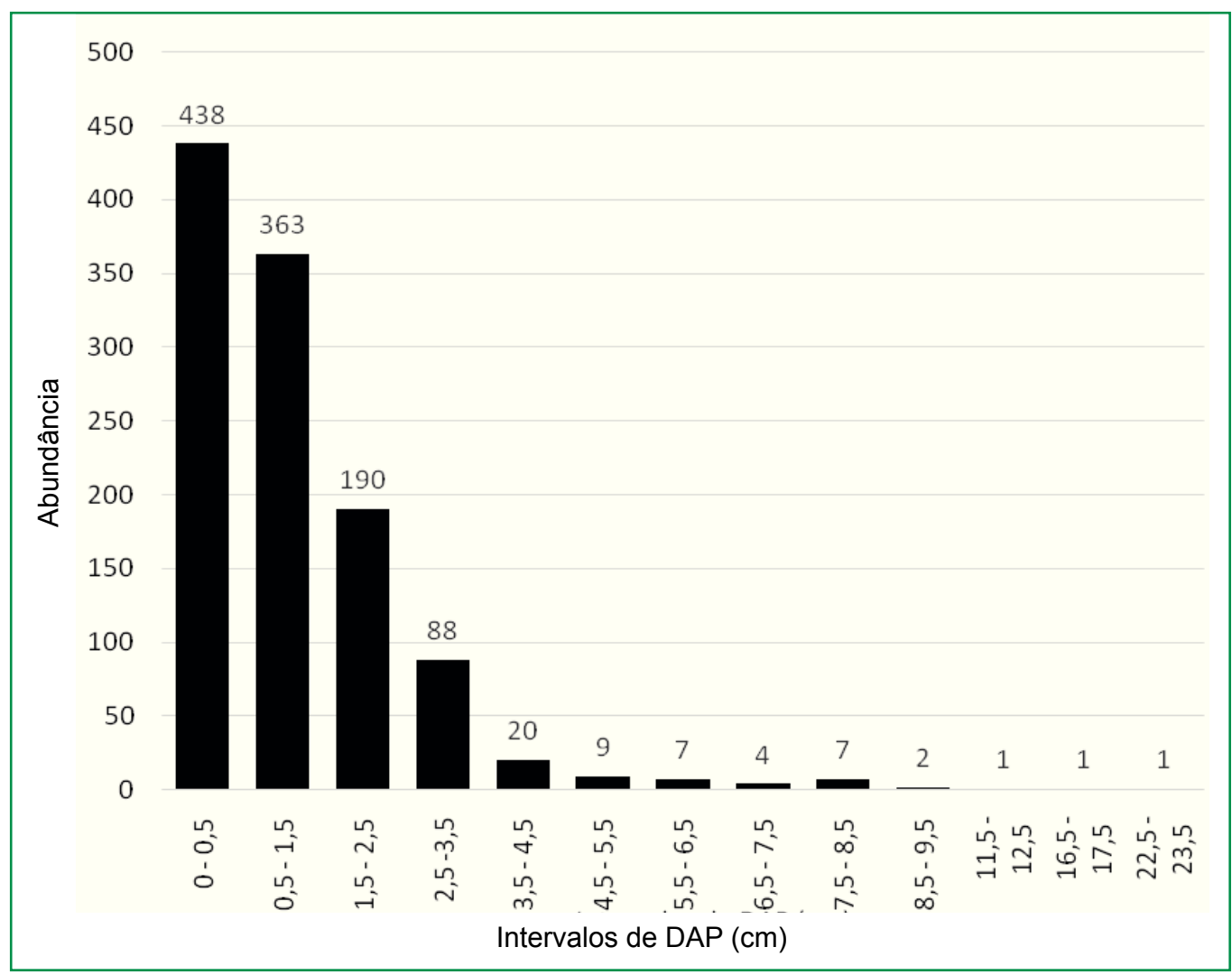

FIGURA 4: Classes de altura de Psychotria nuda (Rubiaceae) em Floresta Ombrófila Densa de Terras Baixas, Joinville, SC.

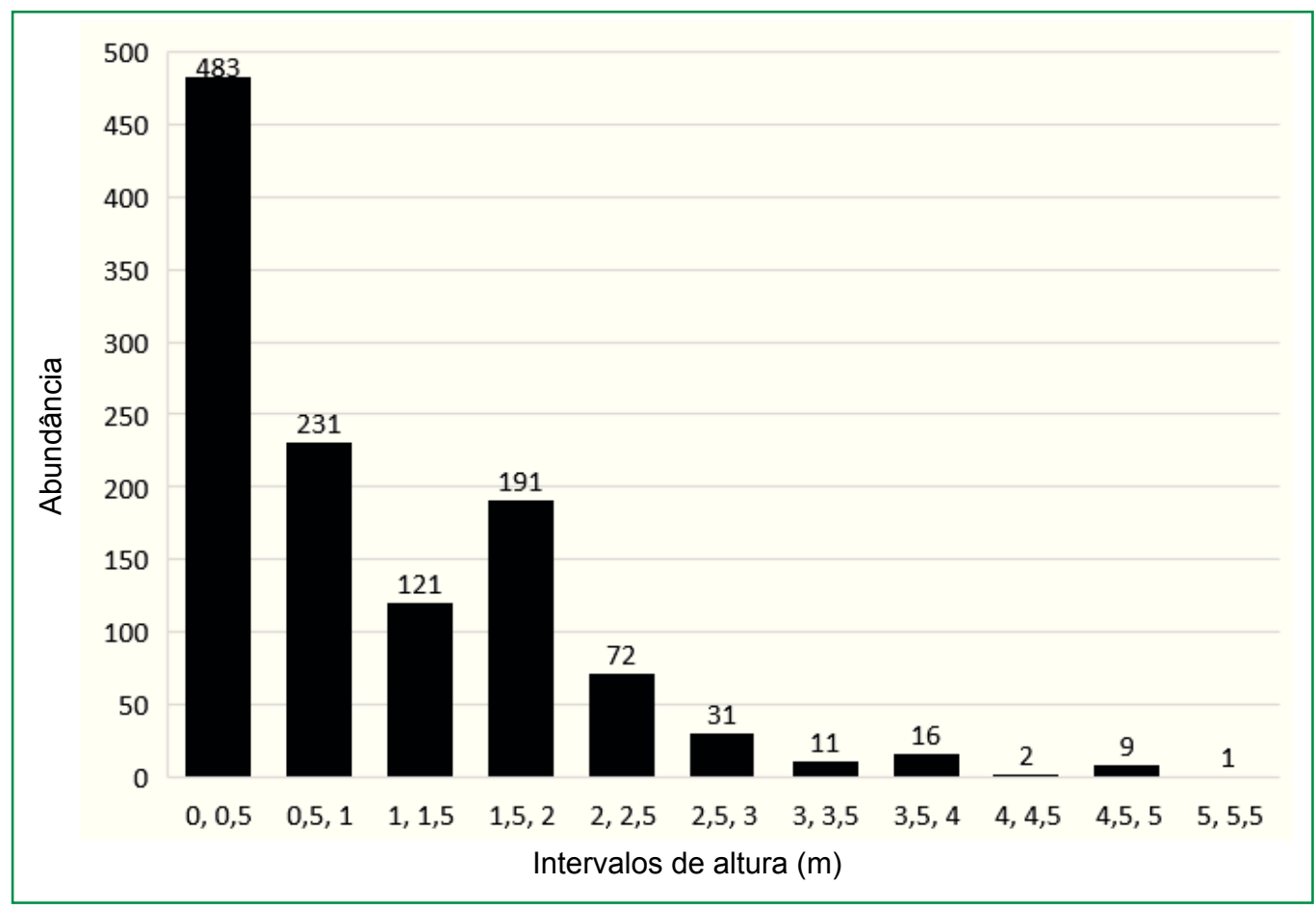




\section{Discussão}

Para o presente estudo foi registrada a espécie Tachyphonus coronatus como sendo a única dispersora de $P$. nuda, ave comumente encontrada em sub-bosque, borda de mata e ocasionalmente em pomares (GWYNNE et al., 2010). Aves da família Thraupidae alimentam-se predominantemente de frutos de arbustos e epífitas, estando entre as mais aptas na dispersão de sementes (SICK, 1997) e, por conseguinte, desempenhando importante papel nos ecossistemas que habitam e na regeneração de ambientes degradados (GALETTI; PIZO, 1996).

$O$ registro de apenas uma espécie dispersora de $P$. nuda pode estar relacionado com o estágio sucessional do fragmento estudado, pois a proporção de espécies zoocóricas costuma ser menor em florestas mais perturbadas e em estágios iniciais de sucessão, em comparação com florestas preservadas, em estádios mais avançados (BROWN; LUGO, 1990; CHAZDON et al., 2007). Estudos indicam que a fauna dispersora é suscetível a perturbações antrópicas, implicando problemas na regeneração e no funcionamento das comunidades florestais (SCHUPP, 1993; WUNDERLE JR., 1997; GUARIGUATA; PINARD, 1998).

Em estudo correlato, Almeida e Alves (2000) avaliaram e descreveram os padrões fenológicos de duas espécies simpátricas, $P$. nuda e P. brasiliensis, comparando-as quanto à fenologia e à distribuição espacial, além de relacionar os eventos fenológicos a fatores abióticos e bióticos (frequência de polinizadores e de frugívoros). Seus resultados apontaram a espécie de ave Lipaugus lanioides (Lesson, 1844) (Cotingidae) como consumidora mais frequente para $P$. brasiliensis, não tendo registro de potenciais dispersores para $P$. nuda. Posteriormente, Almeida et al. (2006) apontaram potenciais aves dispersoras para o gênero Psychotria, relacionando estas à composição nutricional dos frutos. Além de Lipaugus lanioides, novas espécies dispersoras para $P$. brasiliensis foram registradas, tais como: Baryphtengus ruficapillus (Vieillot, 1818) (Momotidae) e Saltator similis (D’Orbigny Lafresnaye, 1837) (Emberizidae). Por outro lado, não foram obtidos registros para $P$. nuda.
Apesar da reconhecida importância das aves como dispersoras de sementes na Mata Atlântica (GALETTI; PIZO, 1996, ALMEIDA; ALVES, 2000; FRANCISCO; GALETTI, 2002; FADINI; DE MARCO JR., 2004), e tendo-se aqui o primeiro registro da interação ornitocórica com P. nuda em remanescente de floresta ombrófila densa no sul do Brasil, a dispersão barocórica é preponderante para a manutenção da espécie no fragmento estudado.

No presente estudo, o valor do Índice de Dispersão de Morisita (Id) encontrado para a população total revela o padrão de distribuição agregado da população de $P$. $n u d a$, caracterizada por poucos indivíduos na classe de adulto e por um maior número de indivíduos nas classes juvenil e de plântula, com evidente redução em altura e diâmetro (Figura 3). Segundo Janzen (1976), o padrão de distribuição agregado é característico de espécies vegetais dispersas por animais ou que realizam a dispersão barocórica, estando relacionado à duração do período de frutificação e à quantidade de sementes produzidas. Conforme apresentado na Figura 4, a maior concentração de indivíduos nas primeiras classes diamétricas caracteriza uma comunidade estoque (CARVALHO, 1982), sendo esse padrão observado em florestas tropicais estáveis, com composição variada de espécies (SCOLFORO et al., 1998), e ocorrendo na maioria das florestas naturais (HARPER, 1990). Cada classe representa uma etapa da fração de regeneração da população de uma determinada espécie ou comunidade (ROLLET, 1978) e, à medida que se aumenta o tamanho da classe diamétrica, a frequência de indivíduos diminui, atingindo o seu menor índice na maior classe, caracterizando uma curva exponencial do tipo "J-invertido" (SCOLFORO et al., 1998). Em termos populacionais, a grande maioria dos indivíduos na primeira classe de diâmetro e com menor representação nas classes de maiores diâmetros sinaliza um balanço positivo entre o recrutamento e a mortalidade das plantas, o que caracteriza a mata como portadora de boa regeneração (SILVA JÚNIOR, 1999).

O padrão de distribuição espacial de Psychotria suterella (Müll. Arg) em fragmentos de Mata Atlântica corrobora o presente estudo, evidenciando um padrão de distribuição agregado para essa espécie (BERTANI, 2006). Os resultados indicaram um padrão de distribuição 
agregado para todas as populações, com exceção da população de um único fragmento isolado, que apresentou distribuição aleatória, sendo explicada pela soma de fatores como baixa densidade e tamanho reduzido dos indivíduos, alto grau de perturbação antrópica e alto grau de abertura do dossel. Entretanto, uma variação no padrão de distribuição espacial de $P$. nuda em fragmentos de floresta ombrófila densa no município de Ubatuba/ SP foi registrada por Corrêa e Santos (2007), os quais encontraram o padrão aleatório para população situada a $80 \mathrm{~m}$ de altitude e padrão agregado para a população localizada a $400 \mathrm{~m}$ de altitude.

Avaliando uma área de Floresta Atlântica pouco perturbada antropicamente, em Ilha Grande/Rio de Janeiro, Almeida e Alves (2000) encontraram o padrão agregado de distribuição para $P$. nuda. Dessa forma, o padrão agregado de distribuição dessa espécie parece também resultar da baixa interação ornitocórica registrada, uma vez que o banco de plântulas está expressivamente associado à área de solo coberta pela copa dos indivíduos adultos. Apesar de outros autores terem registrado esse tipo de distribuição para populações de $P$. nuda em formações de Mata Atlântica do sudeste do país, sugere-se que possa haver interferência na qualidade do fragmento florestal que, por conseguinte, reflete a riqueza de aves frugívoras.

Sevegnani et al. (2009), em levantamento da avifauna no mesmo fragmento em estudo e em áreas adjacentes, identificaram 66 espécies, pertencentes a 30 famílias e 11 ordens, sendo a família Traupidae a mais representativa. Os autores ressaltam que a riqueza de espécies encontrada é semelhante à de outros fragmentos com dimensões semelhantes. Afirmam ainda que a maioria das espécies listadas é considerada típica de borda de floresta em função do efeito de borda que atua sobre o fragmento florestal. A dispersão ornitocórica exclusiva a apenas uma espécie de ave no fragmento estudado pode decorrer da baixa diversidade de avifauna nele encontrado em função do seu estádio sucessional e histórico de supressão de vegetação. Segundo os autores, o fragmento em estudo é ocupado por uma avifauna mais generalista, a qual compete com as espécies especialistas, uma vez que nessa área foram registradas cerca de 66 espécies de aves, sendo apenas 20 frugívoras.
Os resultados permitem concluir que o padrão de distribuição agregado encontrado para a população de P. nuda pode estar relacionado com a falta de um agente dispersor mais eficiente quando comparado à dispersão barocórica, o que justifica o padrão de distribuição agregado. Em termos populacionais, a espécie apresenta uma taxa balanceada entre recrutamento e morte de indivíduos, tendo em vista o elevado número de indivíduos de pequenos diâmetro e altura nas fases de plântula e juvenil, seguido de poucos indivíduos na fase adulta.

\section{Referências}

ALMEIDA, E. M.; ALVES, M. A. Fenologia de Psychotria nuda e $P$. brasiliensis (Rubiaceae) em uma área de Floresta Atlântica no sudeste do Brasil. Acta Botanica Brasilica, Feira de Santana, v. 14, p. 335-346, 2000 .

ALMEIDA, E. M.; COSTA, P. F.; BUCKERIDGE, M. S.; ALVES, M. A. S. Potential bird dispersers of Psychotria in a area of Atlantic forest on Ilha Grande, RJ, Southeastern Brazil: a biochemical analysis of the fruits. Brazilian Journal of Biology, São Carlos, v. 66, n. 1, p. 1-8, 2006.

ALMEIDA-NETO, M.; CAMPASSI, F.; GALETTI, M.; JORDANO, P.; OLIVEIRA-FILHO, A. Vertebrate dispersal syndromes along the Atlantic Forest: broad-scale patterns and macroecological correlates. Global Ecology and Biogeography, Ottawa, v. 17. p. 503-513, 2008.

ALVARES, C.A.; STAPE, J.L.; SENTELHAS, P.C.; GONÇALVES, J. L. M.; SPAROVEK, G. Köppen's climate classification map for Brazil. Meteorologische Zeitschrift, Stuttgart, v. 22, p. 711-728, 2013.

ARRIOLA, I. A.; MELO JÚNIOR, J. C. F. A diversidade de galhas pode predizer o estado de conservação de remanescentes florestais da Mata Atlântica? In: MELO JÚNIOR, J. C. F.; OLIVEIRA, T. M. N. (Org.). Ciências Ambientais: ensaios e perspectivas. Vol. 1. Joinville: Univille, 2017. p. 67-104.

BERTANI, D. F. Ecologia de populações de Psychotria suterella Müll. Arg. (Rubiaceae) em uma paisagem fragmentada de Mata Atlântica. 2006. 126 f. Tese (Doutorado em Biologia Vegetal) Universidade Estadual de Campinas, Campinas. 2006.

BFG - THE BRAZIL FLORA GROUP. Growing knowledge: an overview of seed plant diversity in Brazil. Rodriguésia, Rio de Janeiro, v. 66, p. 1085-1113, 2015.

BORCARD, D.; GILLET, F.; LEGENDRE, P. Numerical ecology with R. New York: Springer, 2011. 319 p.

BROWER, J. E.; ZAR, J. H. Field \& laboratory methods for general ecology. Iowa: W.C. Brown Publishers, 1984. 226 p.

BROWN, S.; LUGO, A. E. Tropical secondary forests. Journal of Tropical Ecology, Winchelsea, v. 6, n. 1, p. 1-32, 1990.

CARVALHO, J. O. P. Análise estrutural da regeneração em floresta tropical densa na região do tapajós no estado do Pará. 1982. 139 f. Dissertação (Mestrado em Ciências Florestais) Universidade Federal do Paraná, Curitiba. 1982. 
CHAZDON, R. L.; LETCHER, S. G.; BREUGEL, M.; MARTÍNEZRAMOS, M.; FRANS BONGERS, F.; FINEGAN, B. Rates of change in tree communities of secondary Neotropical forests following major disturbances. Philosophical Transactions of the Royal Society of London, London, v. 28, n. 362 p. 273-289, 2007.

CLIMATE-DATE. Dados climáticos para cidades mundiais. 2017. Disponível em: <http:/climate-data.org>. Acesso em: 17 abr. 2017.

CORRÊA, C. E.; SANTOS, F. A. M. Distribuição espacial de Psychotria nuda em Floresta Ombrófila Densa, Ubatuba, SP. In: CONGRESSO DE ECOLOGIA DO BRASIL, VIII, 2007, Caxambu. Anais..., Caxambu: Sociedade de Ecologia do Brasil, 2007. Versão eletrônica.

DELPRETE, P. G.; SMITH, L. B.; KLEIN, R. M. Rubiáceas. In: REIS, A. (Ed.). Flora ilustrada catarinense. Vol. 2. Itajaí: Herbário "Barbosa Rodrigues", 2005. p. 349-842.

FADINI, R. F.; DE MARCO JR., P. Interações entre aves frugívoras e plantas em um fragmento de mata atlântica de Minas Gerais. Ararajuba, Londrina, v. 12, n. 2, p. 97-103, 2004.

FERMINO JUNIOR, P. C. P.; PAULILO, M. T. S.; REIS, A.; SANTOS, M. Espécies pioneiras e climáticas da Floresta Ombrófila Densa: anatomia foliar comparada. Insula, Florianópolis, v. 33, p. 21-37, 2004.

FRANCISCO, M. R.; GALETTI, M. Aves como potenciais dispersoras de sementes de Ocotea pulchella Mart. (Lauraceae) numa área de vegetação de cerrado do sudeste Brasileiro. Revista Brasileira de Botânica, São Paulo, v. 25, n. 1, p. 11-17, 2002.

GALETTI, M.; FERNANDEZ, J. C. Palm heart harvesting in the Brazilian Atlantic Forest: changes in industry structure and the illegal trade. Journal of Applied Ecology, London, v. 35 p. 294301, 1998 .

GALETTI, M.; PIZO, M. A. fruit eating by birds in a forest fragment in southeastern Brazil. Ararajuba, Londrina, v. 4, p. 71-79, 1996.

GOMES, M. Rubiaceae. In: LIMA, M. P. M.; GUEDES-BRUNI, R. R. (Ed.). Reserva Ecológica de Macaé de Cima, nova Frigurgo, RJ. Aspectos florísticos das espécies vasculares. Rio de Janeiro: Jardim Botânico do Rio de Janeiro, 1996. p. 345-426.

GORENSTEIN, M. R. Estrutura populacional de Psychotria nuda (Cham \& Schltdl.) Wawra, Hyeronima alchorneoides Allemão e Marlierea obscura Berg. em Floresta Ombrófila Densa Submontana na Ilha do Cardoso, litoral sul de São Paulo. In: MACHADO, G.; PRADO, P. I. K. L (Ed.). Prática da Pesquisa em Ecologia da Mata Atlântica. Cananéia: EDUSP, 2007. p. 1-6.

GUARIGUATA, M. R.; PINARD, M. A. Ecological knowledge of regeneration from seed in neotropical forest trees: implications for natural forest management. Forest Ecology and Management, Amsterdam, v. 11, n. 2, p. 87-99, 1998.

GWYNNE, J. A.; RIDGELY, R. S.; TUDOR, G.; ARGEL, M. Aves do Brasil: Pantanal \& Cerrado. São Paulo: Editora Horizonte, 2010. 322 p.

HARPER, J. L. Population biology of plants. London: Academic Press, 1990. 892 p.

IBGE. Manual técnico da vegetação brasileira. Rio de Janeiro: IBGE, 2012. $276 \mathrm{p}$.

IZA, O. B. Parâmetros de autoecologia de uma comunidade arbórea de Floresta Ombrófila Densa, no Parque Botânico do Morro Baú, Ilhota, SC. 2002. 92 f. Dissertação (Mestrado em Biologia Vegetal) - Universidade Federal de Santa Catarina, Florianópolis. 2002.

JANZEN, D. H. Why bamboos wait so long to flower? Annual Review of Ecology and Systematics, Palo Alto, v. 7, p. 347-391, 1976.

JORDANO, P. Patterns of mutualistic interactions in pollination and seed dispersal: connectance, dependence asymmetries, and coevolution. American Naturalist, Chicago, v. 129, p. 657-677, 1987.

JUDD, W. S; CAMPBELL, C. S; KELlOGG, E. A; STEVENS, P. S; DONOGHUE, M. J. Plant Systematics: a phylogenetic approach. Sunderland: Sinauer Associates, 2008. 607 p.

LAGOS, A. R.; MULLER, B. L. A. Hotspot brasileiro: Mata Atlântica. Saúde e Ambiente, Rio de Janeiro, v. 2, n. 2, p. 35-45, 2007.

MELO, M. M. R. F. Demografia de árvores em Florestal Pluvial Atlântica, Ilha do Cardoso, SP, Brasil. 2000. 141 f. Tese (Doutorado Ciências) - Universidade de São Carlos, São Carlos. 2000.

MMA - MINISTÉRIO DO MEIO AMBIENTE. Mata Atlântica. 2016. Disponível em: <http://www.mma.gov.br/biomas/mataatlantica>. Acesso em: 24 jul. 2017.

MYERS, N.; MITTERMEIER, R. A.; MITTERMEIER, C. G.; FONSECA, G. A.; KENT, J. Biodiversity hotspots for conservation priorities. Nature, London, v. 403, p. 853-858, 2000.

PEREIRA, Z. V.; VIEIRA, M. F.; CARVALHO-OKANO, R. M. Fenologia de floração, morfologia floral e sistema de incompatibilidade em espécies distílicas de Rubiaceae em fragmento florestal do sudeste brasileiro. Revista Brasileira de Botânica, São Paulo,v. 29, n. 3, p. 471-480, 2006.

PIZO, M. A. Seed dispersal and predation in two popu-lations of Cabralea canjerana (Meliaceae) in the Atlan-tic Forest of southeastern Brazil. Journal of Tropical Ecology, Winchelsea, v. 13, p. 559-578, 1997.

POOLE, R. W. An introduction to Quantitative Ecology. New York: McGraw-Hill, Inc., 1974. 532 p.

PRATA, B. E. M.; ASSIS, M. A.; JOLY, C. A. Composição florística e estrutura da comunidade arbórea na transição da Floresta Ombrófila Densa das Terras Baixas - Floresta Ombrófila Densa Submontana do Núcleo Picinguaba/PESM, Ubatuba, sudeste do Brasil. Biota Neotropica, Campinas, v. 11, n. 2, p. 1-15, 2011.

ROBINSON, G. R.; HANDEL, S. N. Forest restoration on a closed landfill: rapid addition of new species by bird dispersal. Conservation Biology, San Francisco, v. 7, p. 271-278, 1993.

ROCHA, C. F. D.; BERGALLO, H. G.; ALVES, M. A. S.; SLUYS, $M$. V. A biodiversidade nos grandes remanescentes florestais do estado do Rio de Janeiro e nas restingas da Mata Atlântica. São Carlos: Rima Editora, 2003. 163 p.

ROLLET, B. Arquitetura e crescimento das florestas tropicais. Belém: SUDAM, 1978. 22 p.

SCHUPP, E. W. Quantity, quality and the effectiveness of seed dispersal by animals. Vegetatio, Perth, v. 107/108, p. 15-29, 1993.

SCOLFORO, J. R. S.; PULZ, F. A.; MELO, J. M. Modelagem da produção, idade das florestas nativas distribuição espacial das 
espécies e a análise estrutural. In: SCOLFORO, J. R. S. (Org.). Manejo florestal. Lavras: UFLA/FAEPE, 1998. p. 189-246.

SEVEGNANI, G. C.; GROSE, A. V.; SOARES, D. C.; CARDOSO, F.; DORNELLES, S. S. Avifauna no fragmento florestal do Jardim Botânico da UNIVILLE e em seu entorno. Revista Univille, Joinville, v. 14, n. 2, p. 25-32, 2009.

SICK, H. Ornitologia brasileira. Rio de Janeiro: Nova Fronteira, 1997. $912 \mathrm{p}$.

SIGRIST, T. Avifauna brasileira: descrição das espécies. São Paulo: Avis Brasilis, 2009. 600 p.

SILVA, M. C.; CASTELETI, C. H. M. Estado da biodiversidade da Mata Atlântica brasileira. In: GALINDO-LEAL. C.; CÂMARA. I. G. (Ed.). Mata Atlântica: biodiversidade, ameaças e perspectivas. São Paulo: Fundação SOS Mata Atlântica, 2005. p. 43-59.

SILVA JÚNIOR, M. C. Composição florística, fitossociologia e estrutura diamétrica na mata de galeria do Monjolo, Reserva Ecológica do IBGE (RECOR), DF. Boletim do Herbário Ezechias Paulo Heringer, Brasília, v. 4, p. 30-45, 1999.
TABARELLI, M.; GASCON, C. Lessons from fragmentation research: improving management and policy guidelines for biodiversity conservation. Conservation Biology, San Francisco, v. 19, p. 734-739, 2005.

TABARELlI, M.; SILVA, J. M. C.; GASCON, C. Forest fragmentation, synergisms and the impoverishment of neotropical forests. Biodiversity and Conservation, New York, v. 13, p. 14191425, 2004.

TAYLOR, C. M. Psychotria. In: WANDERLEY, M. G. L.; SHEPHERD, G. T.; MELHEM, T. S.; GIULIETTI, A. M. (Ed.). Flora fanerogâmica do estado de São Paulo. Vol. 5. São Paulo: Instituto de Botânica, 2007. p. 389-412.

WEISBAUER, M. B.; GIEHL, E. L. H.; JARENKOW, J. A. Padrões morfológicos de diásporos de árvores e arvoretas zoocóricas no Parque Estadual de Itapuã, RS, Brasil. Acta Botanica Brasilica, Feira de Santana, v. 22, p. 425-435, 2008.

WUNDERLE JR, J. M. The role of animal seed dispersal in accelerating native forest regeneration on degraded tropical lands. Forest Ecology and Management, Amsterdam, v. 99, n. 1/2, p. 223-235, 1997. 